\title{
Cardiovascular Activities of an Ayurvedic Preparation Amalaki Rasayan in Rat Model
}

\section{Md. Taimuzzaman Sharif ${ }^{1}$, Shahana Jahan², Kamrun Nahar ${ }^{2}$, Most. Shammi Rahman ${ }^{2}$, Md. Musfequr Rahman Shajjad ${ }^{1}$, Abu Asad Chowdhury ${ }^{1}$, Mohammad A. Rashid ${ }^{1}$ and Mohammad Shah Amran ${ }^{1}$}

\author{
${ }^{1}$ Department of Pharmaceutical Chemistry, Faculty of Pharmacy, University of Dhaka, \\ Dhaka-1000, Bangladesh. \\ ${ }^{2}$ Department of Pharmacy, State University of Bangladesh, Dhaka-1205, Bangladesh
}

Received: April 01, 2017; Accepted: April 16, 2017; Published (Web): July 31, 2017

\begin{abstract}
The importance of traditional or alternative medicines including Ayurvedic drugs are increasing day by day because of their necessary pharmacological actions and fewer side effects. Previous investigators showed hypolipidemic and cardioprotective effects of Amla which is the active ingredient of Amalaki Rasayan. It is an ayurvedic formulation that contains extracts of Phyllanthus emblica plant. Therefore, this study has been conducted to investigate the scientific evidence of its cardioprotective effects in rats by recording electrocardiographic tracings. Rats, of either sex, were treated with preparation containing extracts of Phyllanthus emblica in doses $800 \mu \mathrm{g} / \mathrm{kg}$ bodyweight, $1600 \mu \mathrm{g} / \mathrm{kg}$ body weight and 3200 $\mu \mathrm{g} / \mathrm{kg}$ body weight through intraperitoneal route. Electrocardiogram along with heart rate and other parameters were measuredin rat model before and after administration of Amalaki Rasayan. It was evident that Amalaki Rasayan, at a dose of $800 \mu \mathrm{g} / \mathrm{kg}$, was safe but $1600 \mu \mathrm{g} / \mathrm{kg}$ and $3200 \mu \mathrm{g} / \mathrm{kg}$ produced abnormal activities in the heart. It can be inferred from the study that, the ayurvedic preparation Amalaki Rasayan possesses significant cardioprotective effect.
\end{abstract}

Key words: Amalaki Rasayan, ECG, Heart disease, Rat model, Traditional medicines.

\section{Introduction}

Medicinal plants are one of the principal healthcare resources for the majority of people all over the world. The healing properties of herbal medicines have been recognized in many ancient cultures. The traditional systems such as Ayurveda, Siddha and Unani are part of a time-tested culture and honored by people till today. Pharmaceutical importance of plants has led to adoption of plant extracts commonly known to be used in traditional medicine, as alternative source of remedy (Suresh et al., 2011). Herbal medicines, also called botanical medicines or phytomedicines, refer to the use of any plant seed, berries, roots, leaves, bark or flower for medicinal purposes (Baquar, 2001). The economic significance of medicinal plants stems from the fact that the number of patients suffering from chronic ailments is on the rise and drugs from medicinal plants are more effective in treating such disorders (Deshpande et al., 2006). Medicinal and aromatic plants (MAPs) are produced and offered in a wide variety of products, from crude materials to processed and packaged products like pharmaceuticals, herbal remedies, teas, spirits, cosmetics, sweets, dietary supplements, varnishes and insecticides (Ohrman, 1991; Gorecki, 2002; Lange, 1996). Ayurvedic medicine still are of main choices of the world's populations for primary healthcare because of better cultural acceptability, compatibility with the human body and fewer side effects. Now a days, many Ayurvedic preparations are used for the treatment of different diseases but

Correspondence to: Mohammad Shah Amran; Email: amranms@du.ac.bd 
there are little proven scientific evidence about their proper action and lethal dose. In the present days, the World Health Organisation (WHO) emphasizes on concomitant use of traditional drugs, which are bsed on plant materials, to ensure the total health coverage. A large number of plants are known to be used in the treatment of cardiovascular disorders in different corners of the world. Ayurveda is a Sanskrit term, made up of the words ayus and veda. Ayus means life and Veda means knowledge or science. The term Ayurveda thus means the knowledge of life or the science of life (Laksmi et al., 2011).

Ayurveda is a traditional system of medicine (Courson, 2008) and used as a wide range of modalities to create health and wellbeing. It is used to restore the physical, mental and emotional balance in patients, thereby improving health, preventing disease (prophylaxis) and also treating any current illness (Mazumder et al., 2011).The World Health Organization and National Institute of Health, USA have also recommended the use of Ayurvedic drugs in the name of complementary/alternative medicine (CAM) system, because these drugs have fewer side effects and give necessary pharmacological actions (Chopra and Doiphode, 2002; Dodds, 2008; Gogty et al., 2002).

Amalaki Rasayan is prepared from whole fruit of Phyllanthus emblica, also known as emblic myrobalan, Indian gooseberry, Malacca tree, or amla of the family Phyllanthaceae. It is known for its edible fruit of the same name. Amalaki Rasayan is an Ayurvedic formulation which is beneficial for brain, eyes, heart, liver, skin and hair. It improves the functions and health of these organs. It is manufactured as liquid by arista process (BNFAM, 1992). In this paper we highlighted the effects of this formulation on cardiac system.

\section{Materials and Methods}

Drug: Amalaki Rasayan was purchased from Shree Kundeshwari Oushadhalaya, Dhaka. It was presented as $500 \mathrm{ml}$ in glass bottle.

Instruments: Veterinary ECG machine (EDAN VET 300 model) was used to carry out the experiment. The EDAN VET-300 is suitable equipment for laboratory experiments with animals for measuring ECG. It is simple and easy to use, lightweight and portable. Interpretative analysis included in the form of automatic measurement calculation.

Selection of animals: A total of 40 rats of either sex, weighing about 130-150 g, aged 2 months were purchased from the animal house of the Department of Pharmacy, Jahangirnagar University, Savar, Dhaka, Bangladesh. The rats were divided into four groups:

Group I: Rats were given only normal food and water. This group of rats is referred as Control rats.

Group II: Rats were given normal food and water. They received Amalaki Rasayan at a dose of $800 \mu \mathrm{g} / \mathrm{kg}$ body weight.

Group III: Rats were given normal food and water. They received Amalaki Rasayan at a dose of $1600 \mu \mathrm{g} / \mathrm{kg}$ body weight.

Group IV: Rats were given normal food and water. They received Amalaki Rasayan at a dose of $3200 \mu \mathrm{g} / \mathrm{kg}$ body weight.

All the rats were acclimatized to the new environment for a period of one week. During the experimental period, the rats were kept in a well ventilated animal house maintained at $25^{\circ} \mathrm{C}$. They were supplied with standard pellets and fresh drinking water. All the rats were kept in cage and maintained with natural $12 \mathrm{~h}$ light and dark cycle in the animal house of Institute of Nutrition and Food Science, University of Dhaka, Bangladesh.

Preparation of dose: The dose was calculated from adult human dose of $10 \mathrm{ml}$ as a single dose. The dose calculation is given in the Table 1 .

Experimentation: For anesthesia, $50 \mathrm{mg} / \mathrm{kg}$ Ketamine was administered intraperitoneally. The electrodes were connected to the left arm, right arm, left leg, right leg and rib joint. Auto option was selected to get rhythm from standard limb lead I, II, III, avR, avL, avF, V. Finally standard limb lead I and II were used for characterization of ECG. Rhythm mode was also used and standard limb lead 
II recording were used for calculation of ECG parameters.

ECG parameters: ECG parameters were recorded and analyzed to find out the effects of the test drug. The ECG parametersare summarized in Table 2. A schematic tracing of ECG record is shown in Figure 1. These tracings were used as standard to calculate the measured values of ECG parameters.

Table 1. Calculation of dose (' $X$ ' is body weight of the rats) where normal human dose is $200 \mathrm{mg} / \mathrm{kg}$.

\begin{tabular}{lcc}
\hline $\begin{array}{l}\text { Concentration } \\
\text { (as expressed by "X”) }\end{array}$ & $\begin{array}{c}\text { Concentration } \\
\text { (as expressed by } \mu \mathrm{g} / \mathrm{kg} \text { ) }\end{array}$ & $\begin{array}{c}\text { Action } \\
\text { sought }\end{array}$ \\
\hline $1 / 16 \mathrm{X}$ & 100 & Less action \\
$1 / 12 \mathrm{X}$ & 133 & Less action \\
$1 / 8 \mathrm{X}$ & 200 & Less action \\
$1 / 4 \mathrm{X}$ & 400 & Less action \\
$1 / 2 \mathrm{X}$ & 800 & Proper action \\
$\mathrm{X}$ & 1600 & Slightly toxic \\
$2 \mathrm{X}$ & 3200 & More toxic \\
$4 \mathrm{X}$ & 6400 & Lethal dose \\
$8 \mathrm{X}$ & 12800 & Lethal dose \\
\hline
\end{tabular}

Table 2. ECG Parameters.

\begin{tabular}{lc}
\hline Parameters of ECG & Duration (ms) \\
\hline P wave & $\leq 100$ \\
QRS complex & $80-110$ \\
Q wave & 40 \\
R wave & 200 \\
S wave & $60-10$ \\
T wave & 160 \\
U wave & 80 \\
PR interval & $120-200$ \\
ST segment & $\leq 200$ \\
R-R interval & $600-1200$ \\
Q-T interval & $350-430$ \\
\hline
\end{tabular}

ECG paper speed: The paper moved at a rate of $25 \mathrm{~mm} / \mathrm{second}$. Time was measured horizontally. Each small block is $1 \mathrm{~mm}$ which is equal to 0.04 seconds and $0.1 \mathrm{mV}$. Each bold block is equal to 0.2 seconds. Amplitude was measured vertically in $\mathrm{mV}$.

\section{Results}

ECG tracings were recorded before and after administration of the test drug and it was found that in control group the normal heart rate of rats was within 195-282 bpm (normal range being 250-350 bpm)and ECG tracing showed that every parameters were within the normal range (Figure 2).

When Amalaki Rasayan was administered at a dose of $800 \mu \mathrm{g} / \mathrm{kg}$, no change in the heart rate and other ECG parameters were observed. It was indicated that $800 \mu \mathrm{g} / \mathrm{kg}$ is quite safe dose for the rats (Figure 3).

After administration of $1600 \mu \mathrm{g} / \mathrm{kg}$, it showed some abnormalities such as SA nodal block which was an evident from missing beats (Figure 4).

After administration of $3200 \mu \mathrm{g} / \mathrm{kg}$ of the drug, the heart rate decreased to about $67 \mathrm{bpm}$. It indicated that Amalaki Rasayan produced bradycardia and ultimately leading to the deathof the animals (Figure 5a-d) producing various types of severe arrhythmias.

It indicated that $3200 \mu \mathrm{g} / \mathrm{kg}$ is a very lethal dose and this dose of the drug produced all types of arrhythmias.

Data from auto mode: The auto mode of the ECG machine was that mode where heart rate, $P$ wave, PR interval, QRS duration was shown and measured. Using the auto mode it could be known about increase or decrease in heart rate and other 
parameters as listed in Table 2. The data obtained from the ECG machine after administration 800 $\mu \mathrm{g} / \mathrm{kg}$ in auto mode showed in the Table 3 .

Table 3 showed the ECG parameters after administration of $800 \mu \mathrm{g} / \mathrm{kg}$ of Amalaki Rasayan. Pretreatment row shows the values in control condition. ECG parameters were calculated after 10 min of administration of drug. At this dose, the heart rate increased, $\mathrm{P}$ duration decreased, $\mathrm{PR}$ interval decreased followed by increased for some time and then came to normal value. All these indicated that $800 \mu \mathrm{g} / \mathrm{kg}$ was safe dose for the animal.

The data of auto mode obtained from ECG tracings after administration $3200 \mu \mathrm{g} / \mathrm{kg}$ in auto mode shown in the Table 4.

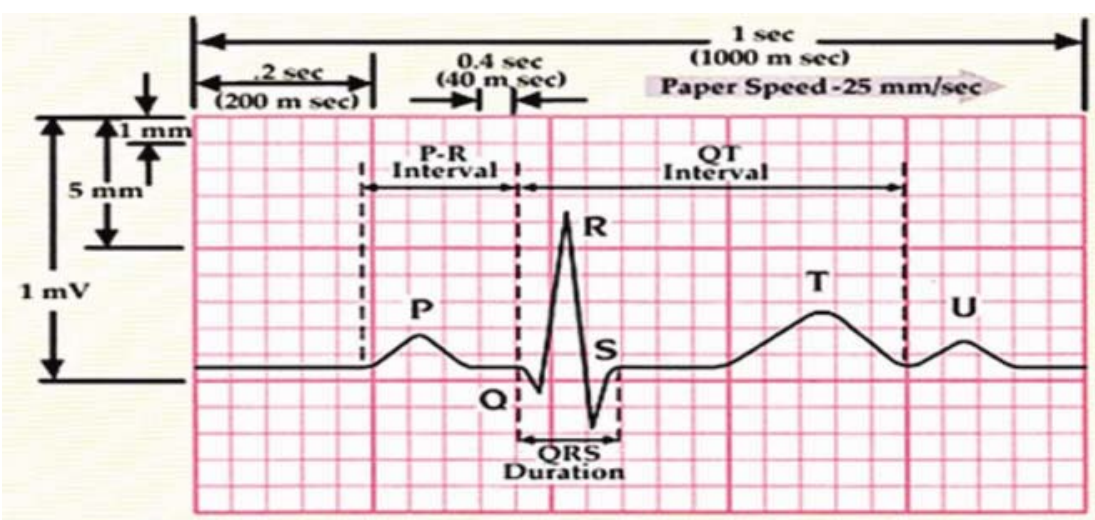

Figure 1. Schematic presentation of an ECG tracing. In the vertical axis, 1 small square $=1 \mathrm{~mm}(0.1 \mathrm{mV}), 1$ large square $=5$ $\mathrm{mm}(0.5 \mathrm{mV})$ and 2 large square $=10 \mathrm{~mm}(1 \mathrm{mV})$, and in the horizontal axis, 1 small square $=0.04 \mathrm{~s}(40 \mathrm{~ms}), 5 \mathrm{small}$ square $=0.2 \mathrm{~s}(200 \mathrm{~ms})$ and 25 small square $=1 \mathrm{~s}(1000 \mathrm{~ms})$.

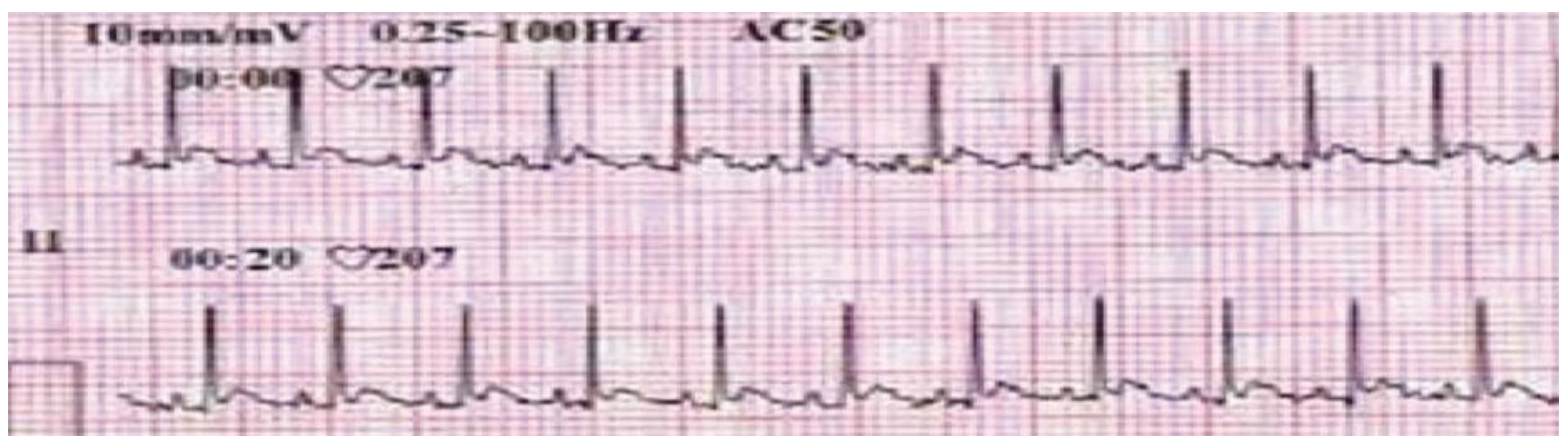

Figure 2.Normal ECG tracings of the rat heart.

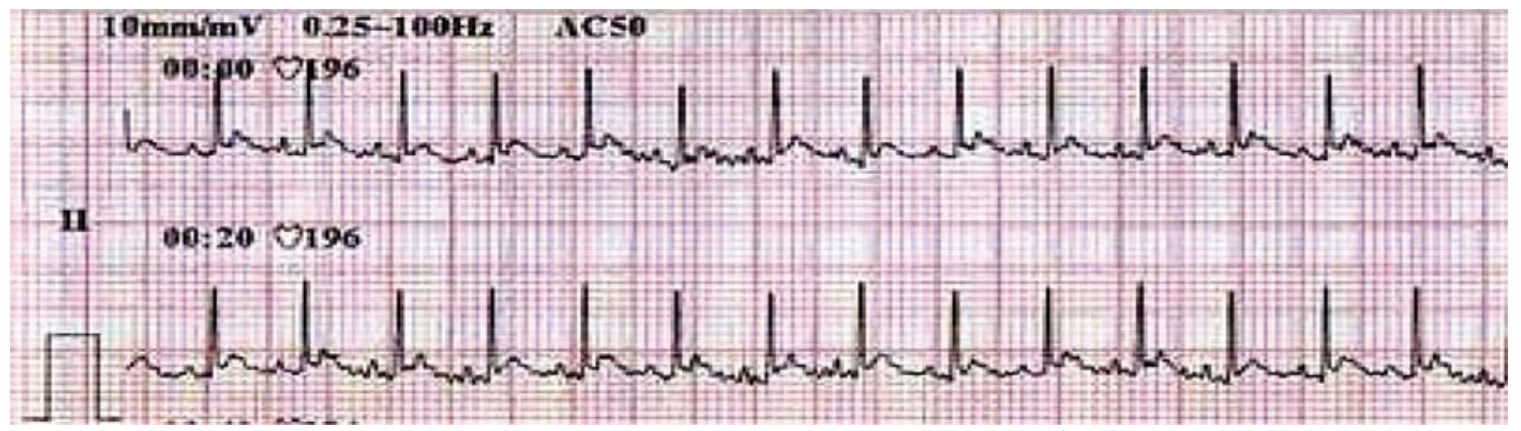

Figure 3. ECG tracing after administration of $800 \mu \mathrm{g} / \mathrm{kg}$ of Amalaki Rasayan. 


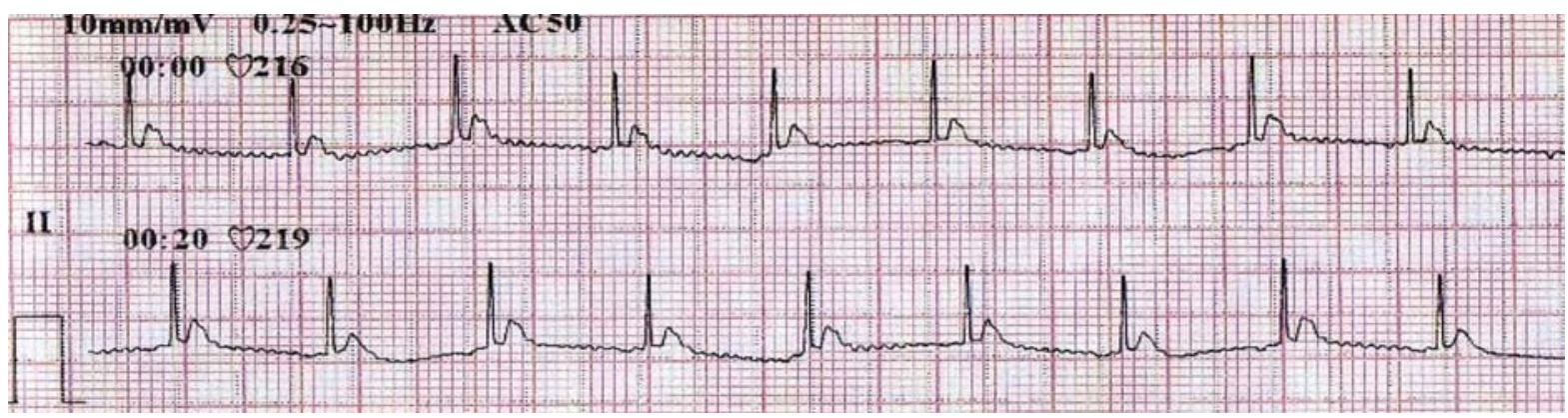

Figure 4. Typical ECG tracings of the standard limb lead I and II after intraperitoneal administration of $1600 \mu \mathrm{g} / \mathrm{kg}$ of drug.
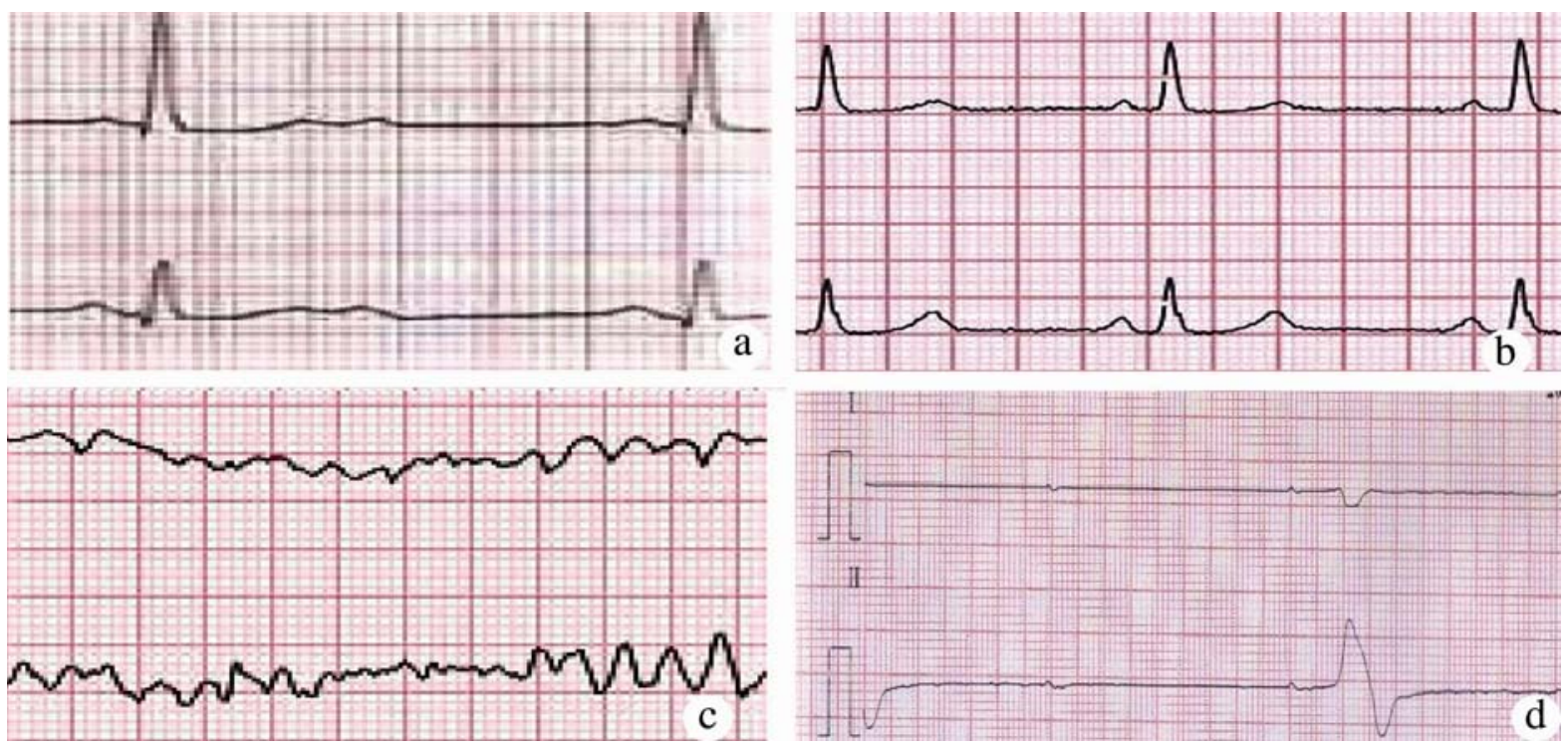

Figure 5. Typical ECG tracings of the standard limb lead I and II after intraperitoneal administration of $3200 \mu \mathrm{g} / \mathrm{kg}$ of drug. Panels (a) and (b) show AV nodal block as well as SA nodal block, Panel (c) and Panel (d) show ventricular fibrillation and dying conditions of the animal, respectively. The vertical line indicates $\mathrm{mV}$ and the horizontal line indicates time in second (s).

Table 3. Different ECG parameters after administration of Amalaki Rasayan at a dose of $800 \mu \mathrm{g} / \mathrm{kg}$. The data were shown as mean of 9 similar experiments $(n=9)$ in autoMode. $(m s=$ mili second, $b p m=$ beat per minute).

\begin{tabular}{lcccc}
\hline Time $(\mathrm{min})$ & HR $(\mathrm{bpm})$ & P duration $(\mathrm{ms})$ & PR interval $(\mathrm{ms})$ & QRS duration $(\mathrm{ms})$ \\
\hline Pretreatment & 216.5 & 42.3 & 90 & 103.6 \\
10 & 280.3 & 42 & 78.3 & 126 \\
15 & 241 & 25.6 & 80.3 & 115.5 \\
20 & 259.5 & 21.3 & 83.5 & 126.8 \\
25 & 245 & 55.6 & 78 & 138.3 \\
30 & 230.5 & 57.5 & 90.6 & 159.2 \\
35 & 242.6 & 27.3 & 87.5 & 154 \\
40 & 255.5 & 31.5 & 95.3 & 142.5 \\
45 & 262.5 & 28.6 & 98.5 & 156 \\
\hline
\end{tabular}


Table 4. Different ECG parameters after administration of Amalaki Rasayan at a dose of $3200 \mu \mathrm{g} / \mathrm{kg}$. The data were shown as mean of 9 similar experiments $(n=9)$ in auto mode.

\begin{tabular}{lcccc}
\hline Time $(\mathrm{min})$ & HR $(\mathrm{bpm})$ & Pduration $(\mathrm{ms})$ & PR interval & QRS duration $(\mathrm{ms})$ \\
\hline Pretreatment & 216.5 & 42.3 & 90 & 103.6 \\
10 & 273.5 & 42 & 64 & 170 \\
15 & 302.5 & 37 & 55.6 & 184.5 \\
20 & 229.5 & 75.6 & 110 & 145.3 \\
25 & 106.5 & 98.5 & 156.3 & 172.8 \\
30 & 95.5 & 51 & 183 & 118.5 \\
35 & 106.5 & 37 & 156 & 118 \\
40 & 67 & 0 & 104 & 104 \\
45 & 75 & 0 & 0 & 92 \\
\hline
\end{tabular}

Table 4 showed the numerical values of different ECG parameters after administration of $3200 \mu \mathrm{g} / \mathrm{kg}$ of Amalaki Rasayan. Pretreatment row shows the normal values. The ECG parameters were calculated after $10 \mathrm{~min}$. It was observed that heart rate decreased severely; P duration, PR interval and QRS duration also decreased dramatically. All these indicated that $3200 \mu \mathrm{g} / \mathrm{kg}$ was a lethal dose leading to dyeing condition of animals.

Data from rhythm mode: The rhythm mode was that mode where leads I, II, III, aVR, aVL, aVF, $\mathrm{V}$ were located. This mode showed RR average interval, $R R$ maximum interval and $R R$ minimum interval. The data obtained from machine after administration $800 \mu \mathrm{g} / \mathrm{kg}$ in rhythm mode is shown in the Table 5.
Table 6 displayed abnormal total $\mathrm{R}$ number, RR average, $R R$ maximum interval and $R R$ minimum interval. In the ECG interpretation curve shown in control mode, the normal heart rate of rats which was 238-282 bpm. But when Amalaki Rasayan was administered at a dose of $800 \mu \mathrm{g} / \mathrm{kg}$, no change in the heart rate was observed. After administration of 1600 $\mu \mathrm{g} / \mathrm{kg}$, it revealed some abnormalities such as SA nodal block, atrial fibrillation, AV nodal block, right bundle branch block andleft bundle branch block. But after administration of $3200 \mu \mathrm{g} / \mathrm{kg}$ of the drug, the heart rate decreased to $67 \mathrm{bpm}$. It indicated that Amalaki Rasayan produced marked bradycardia and ultimately leading to the death of the animals.

Table 5. Different ECG parameters after administration of Amalaki Rasayan at a dose of $800 \mu \mathrm{g} / \mathrm{kg}$. The data were shown as mean of 9 similar experiments $(n=9)$ in rhythm mode.

\begin{tabular}{lccccc}
\hline Time (min) & Total R number & HR (bpm) & RR avg interval (ms) & $\begin{array}{c}\text { RR max interval } \\
(\mathrm{ms})\end{array}$ & $\begin{array}{c}\text { RR min } \\
\text { interval (ms) }\end{array}$ \\
\hline Pretreatment & 189.6 & 239 & 255.3 & 546.3 & 182.5 \\
10 & 236.8 & 238.8 & 254.17 & 519.4 & 152.4 \\
15 & 247.6 & 246.3 & 255.6 & 462.6 & 195.7 \\
20 & 217.3 & 252.5 & 246.6 & 423.83 & 166.5 \\
25 & 260.8 & 263.4 & 238 & 359.4 & 161.3 \\
30 & 245.33 & 270 & 233.5 & 379 & 182 \\
35 & 282.2 & 282 & 213.4 & 405.2 & 195.5 \\
40 & 263.6 & 267.5 & 227.8 & 347.33 & 197.5 \\
45 & 248.8 & 251.5 & 242 & 391.16 & 189.8 \\
\hline
\end{tabular}


In Table 6, the pretreatment column showed the results in control condition. The calculation of data started after $10 \mathrm{~min}$. It was observed that total $\mathrm{R}$ number, RR average interval, $R R$ maximum interval and $\mathrm{RR}$ minimum interval all remained static after administration of $800 \mu \mathrm{g} / \mathrm{kg}$ of the drug.

Table 6 highlighted the results of ECG parameters after administration of $3200 \mathrm{mg} / \mathrm{kg}$. It was observed that the total $\mathrm{R}$ number decreased but $\mathrm{RR}$ average interval, RR maximum interval and $R R$ minimum interval increased drastically. These results suggested that $3200 \mu \mathrm{g} / \mathrm{kg}$ was a lethal dose and it affected all parameters of ECG tracings which indicated that the dose produced all types of arrhythmia.

The data obtained after administration 3200 $\mu \mathrm{g} / \mathrm{kg}$ in rhythm mode were shown in the Table 6.

Table 6. Different ECG parameters after administration of Amalaki Rasayan at a dose of $3200 \mu \mathrm{g} / \mathrm{kg}$. The data were shown as mean of 9 similar experiments $(n=9)$ in rhythmmode.

\begin{tabular}{cccccc}
\hline Time (min) & Total R number & HR (bpm) & RR avg interval (ms) & RR max interval (ms) & RR min interval (ms) \\
\hline Pretreatment & 189 & 239 & 255.3 & 546.3 & 182.5 \\
10 & 286.7 & 289 & 212.6 & 161 & 217 \\
15 & 220.5 & 223 & 296.6 & 525 & 205 \\
20 & 162.5 & 163 & 979.8 & 593.5 & 164.5 \\
25 & 95.6 & 92 & 646.6 & 12007 & 510 \\
30 & 53.8 & 54 & 1098 & 2614.5 & 531 \\
35 & 33.6 & 46 & 1308 & 1839 & 682 \\
40 & 49.6 & 47 & 1203 & 754 & 217 \\
45 & 60 & 67 & 566.6 & & 640 \\
\hline
\end{tabular}

\section{Discussion}

The experiments were performed in rat model with the drug at different doses using the intraperitoneal route and ECG tracing were recorded to explore the cardiac activity. Prolong use of traditional medicine and usage at large dose may cause injury to the related organ (heart, liver, kidney; heart was considered in this study) and produce drug induced effects which might prove lethal to the subjects. We observed that formulation of Phyllanthus emblica offered cardioprotection at 800 $\mu \mathrm{g} / \mathrm{kg}$. This finding is similar to our previous findings with other traditional medicines (Rahman et al., 2013; Islam et al., 2014).In another study in rats it was observed that Phyllanthus emblica dissolved in water preserved cardiac tissue during ischemiareperfusion injury. It also increased the production of nitric oxide which is vasodilator, decreased the low density lipoprotein, total cholesterol and triglyceride (Thirunavukkarasu et al., 2015).

\section{Conclusion}

It was found that $800 \mu \mathrm{g} / \mathrm{kg}$ was normal dose, $1600 \mu \mathrm{g} / \mathrm{kg}$ was slightly toxic but $3200 \mu \mathrm{g} / \mathrm{kg}$ was lethal to the rats. We, therefore, concluded that Amalaki Rasayan is safe to cardiac muscle at a dose of $800 \mu \mathrm{g} / \mathrm{kg}$. But at long time use or at a high dose it could cause different cardiac abnormalities. Similarly, the effects of this drug to other vital organs of the body need to be evaluated. Study at cellular and molecular level with this drug is necessary to get more insight into the pharmacological actions of this drug.

\section{Acknowledgement}

1. This research work was supported by Higher Education Quality Enhancement Project (HEQEP), AIF, Round-III, Window-2, CP-3258, University Grants Commission (UGC), Bangladesh. 
2. Authors are thankful to Professor Dr. Sheikh Nazrul Islam, Institute of Nutrition and Food Science, University of Dhaka, Bangladesh for his kind permission to use their animal house.

\section{Conflict of Interest}

The authors declare that no conflict of interest exists.

\section{Limitation of Study}

We could not use any standard product.

\section{Ethical Approval}

All authors hereby declared that all experiments were examined and approved by the Ethical review committee, Faculty of Pharmacy, University Dhaka, Dhaka-1000, Bangladesh and were therefore been performed in accordance with the ethical standards laid down in the 1964 Declaration of Helsinki.

\section{References}

Bangladesh National Formulary of Ayurvedic Medicine 1992. (Approved by the Government of Bangladesh vide Ministry of Health and Family Welfare Memo No. Health-1/Unani-2/89/ (Part-1) 116 dated 3-61991): 83-84.

Baquar, S.R. 2001. Textbook of Economic Botany, Feroz sons (Pvt.) Ltd., Lahore, Pakistan.

Chopra A and Doiphode VV 2002. Ayurvedic medicinecore concept, therapeutic principles, and current relevance. Medical Clinics of North America, 86, 7588.

Courson W.A. 2008. State licensure and ayurvedic practice: planning for the future, managing the present. Newsletter of the National Ayurvedic Medical Association [online journal].

Deshpande, R.S., Neelakanta, N.T. and Hegde, N 2006. Cultivation of medicinal crops and aromatic crops as a mean of diversification in agriculture: eIX/ADRT/115.

Dodds, J.A. 2008. Know your CAM provider. Bulletin of the American Academy of Orthopedic Surgeons/American Association of Orthopedic Surgeons [online journal].
Gogtay, N.J., Bhatt, H.A. and Dalvi, S.S. 2002. The use and safety of non-allopathic Indian medicines. Drug Safety, 25, 1005-1019

Gorecki, P. 2002. Vitafoods und Kosmetika: Arzneipflanzen erobern sich neue Wirkungsbereiche. Drogenreport, 28, 9-15.

Lakshmi T, Anitha Roy and Geetha R.V. 2011. Acacia Catechu Willd-A Gift from Ayurveda to Mankind -A Review. T. Ph. Res. 5, 273-293.

Lange, D. 1996. Untersuchungen zum Heilpflanzenhandel in Deutschland. EinBeitrag zum internationalen Artenschutz. Bundesamt für Naturschutz, Bonn-Bad Godesberg.

Mazumder Papiya Mitra, Das Saumya, Das Sanjita, Das Manas Kumar 2011. Phyto-Pharmacology of Berberis aristata DC. J. of Drug Delivery \& Therapeutics. 1,4650 .

Md. Tauhid-Ul Islam, Md. Abdus Samad Bhuiyan, Md. Musfequr Rahman Shajjad, Md. Taimuzzaman Sharif, Md. Zakir Sultan, Asma Rahman, Md. Akter Hossain, Abu Asad Chowdhury and Mohammad Shah Amran 2014. A study of prophylactic effect against diabetes of two Ayurvedic drugs Jambadyarista and Bohumutrantak Ras in normal as well as alloxaninduced diabetic rats. British J. Pharm.Res. 4, 19451955.

Most. Shammi Rahman, Shahana Jahan, Kamrun Nahar, Nazia Islam, Danis Rahman, Ridwan Bin Rashid, Abu Asad Chowdhury, Rebecca Banoo and Mohammad Shah Amran 2013. Evaluation of cardiovascular activity of an Ayurvedic product Mrityunjay in rat model; Bangladesh Pharma. J. 16, 99-105.

Ohrmann, R 1991. Pflanzenextrakte in Haushaltsprodukten. Dragoco Report (Holzminden) 3, 67-76.

Suresh Kumar, Rohit Kumar and Altaf Khan (2011). Medicinal plant resources: Manifestation and prospects of life-sustaining healthcare. Continental $J$. Biological Sci.4, 19-29.

Thirunavukkarasu, M., Selvaraju, V., Tapias, L., Sanchez, J.A., Palesty, J.A. and Maulik, N. 2015. Protective effects of Phyllanthus emblica against myocardial ischemia-reperfusion injury: the role of PI3kinase/glycogen synthase kinase $3 \beta / \beta$-catenin pathway, J. Physiol Biochem. 71, 623-33. 